\title{
CORRECTION
}

\section{Correction to: A Comprehensive Review on Human Aichi Virus}

\author{
Enrique Rivadulla ${ }^{1} \cdot$ Jesús L. Romalde ${ }^{1}$ (D)
}

Published online: 2 December 2020

(C) Wuhan Institute of Virology, CAS 2020

\section{Correction to: Virologica Sinica https://doi. org/10.1007/s12250-020-00222-5}

The Fig. 5 in this article is updated. The new Fig. 5 is shown below.

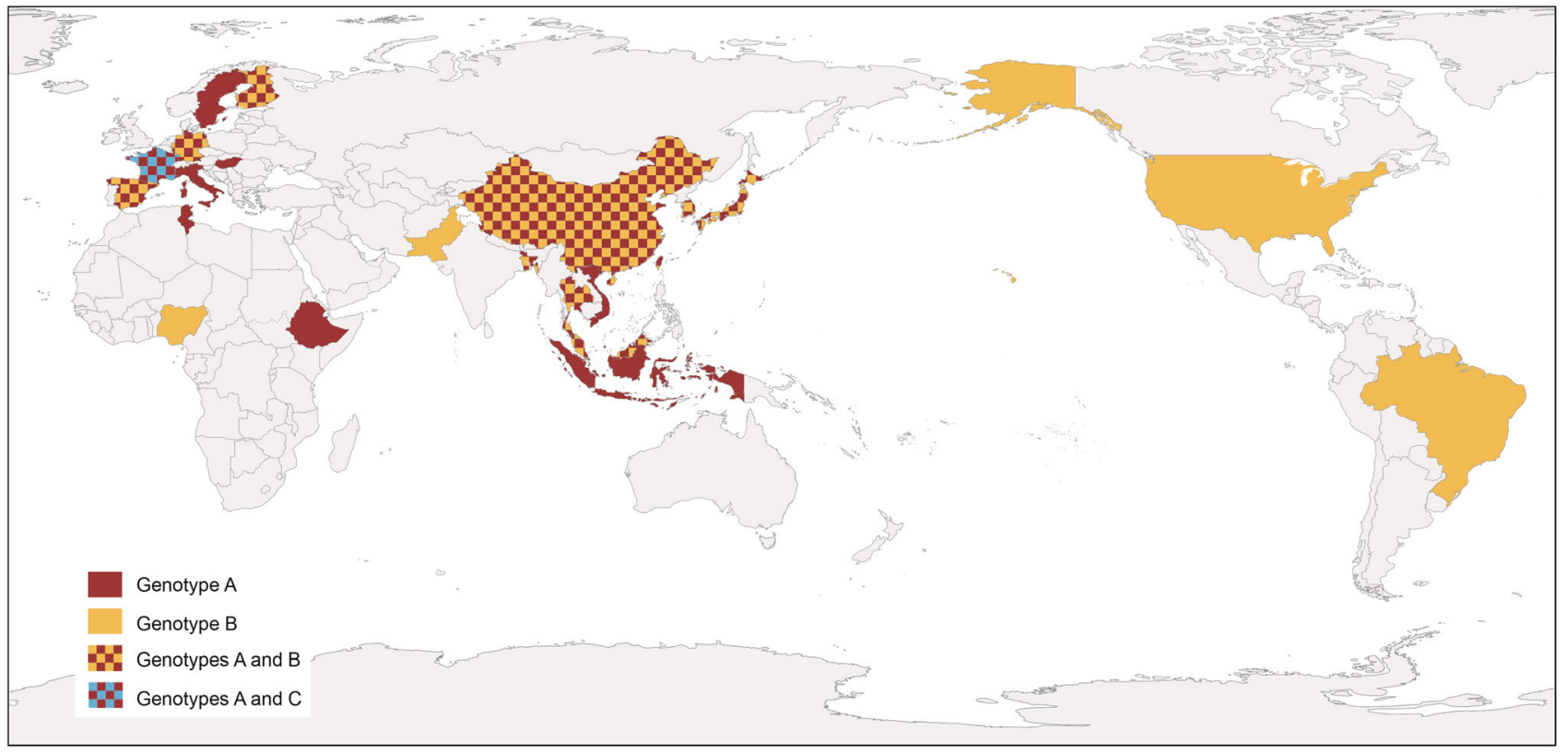

Fig. 5 Worldwide distribution of human AiV genotypes. Data from AiV related gastroenteritis outbreaks and environmental samples.

The original article can be found online at https:// doi.org/10.1007/s12250-020-00222-5.

$\triangle$ Jesús L. Romalde

jesus.romalde@usc.es

1 Departamento de Microbiología y Parasitología, CIBUS-

Facultad de Biología, Universidade de Santiago de

Compostela, 15782 Santiago, Spain 